\title{
Rickettsioses do grupo das febres maculosas em viajantes argentinos
}

\author{
Spotted fever group rickettsial disease in argentinean travelers \\ Olindo Martino1, Tomás Orduna1, Leonardo Lourtau1, Pablo Scapellato, \\ Beatriz Cernigo ${ }^{2}$ e Alfredo Seijo ${ }^{2}$
}

\begin{abstract}
Resumo Durante o ano de 1996, foram atendidos no ambulatório de medicina de viajantes, quatro pacientes procedentes do sul da África com diagnóstico de rickettsiose. Todos eles apresentaram febre, dor de cabeça e presença de escara cutânea. Às 48 horas de iniciado o quadro, um dos pacientes evidenciou uma erupção máculo-papular, enquanto que os restantes desenvolveram um exantema vesicular e crostoso. A reação de Weil-Felix mostrou-se negativa e a sorologia para Rickettsia conorii por imunofluorescência foi positiva em todos os casos. Nenhum dos pacientes recordava haver sofrido picada de insetos ainda que tenham permanecido ou transitado por pastagens em regiões agrestes. Todos receberam tratamento com doxiciclina com evolução clínica satisfatória.
\end{abstract}

Palavras-chaves: Rickettsioses. Febre maculosa. Medicina do viajante.

Abstract During 1996, four patients that returned from South Africa suffering from rickettsiosis were attended at the Traveler's Medicine practice of our hospital. All of them presented fever, headache and cutaneous scar. One of these presented maculopapular rash, while the rest developed a vesicular rash. The Weil-Felix reaction was negative and the immunofluorescence test for Rickettsia conorii was positive in all cases. None of the patients remembered having been bitten by any insects, however all of them had been staying in or going through a wild environment. All the patients were treated with doxycycline and presented a good outcome.

Key-words: Rickettsiosis. Spotted fever group rickettsial disease. Travel medicine.

As enfermidades produzidas por Rickettsias tem ampla distribuição mundial. Vários gêneros e espécies da vasta família Rickettsiaceae mantém ciclos zoonóticos na natureza ${ }^{1}{ }^{2} 14$. Nos últimos anos se reportaram casos clínicos de febre botonosa produzida pro Rickettsia conorii no Uruguai ${ }^{11}$ como também de outras rickettsioses no resto da América Latina ${ }^{6,10,12}$. Apesar disso são escassos os estudos na Argentina. Recentemente, se tem obtido dados autóctones sobre a circulação de Coxiella burnetti $i^{15} \mathrm{e}$ Rickettsia rickettsii na província de Jujuy ( Remondegu C: Comunicação pessoal, 1995).

No ano de 1935, Salvador Mazza e Miguel Jörg, comunicaram um caso de gangrena do membro inferior em habitante da localidade de Tinogasta, província de Catamarca, cujo estudo anatomopatológico demonstrou a nível vascular a presença de alterações compatíveis com lesões procuradas por rickettsias ${ }^{9}$.

Os movimentos migratórios, o turismo e atividades realizadas em áreas endêmicas do exterior, possibilitam a introdução de agentes infecciosos desconhecidos em nosso meio, tais como rickettsioses exóticas, situação que leva a um risco sanitário indubitável ao incorporá-las a nossos ecossistemas autóctones.

O grupo das febres maculosas inclui entre outros agentes tais como $R$. conorii e Rickettsia africae responsáveis pela febre botonosa (febre maculosa mediterrânea, febre sulafricana por picada de carrapato) ${ }^{5} 16$. Com distribuição geográfica distinta, ambos agentes se encontram em território sulafricano.

Depois de um período de incubação variável entre uma e duas semanas, a enfermidade se inicia com a formação de uma ou mais escaras escuras, testemunha do lugar da picada do artrópode vetor. Dias depois, aparece febre, cefaléia e um exantema maculopapuloso que na febre botonosa é efêmero, enquanto que na Rickettsiose pustulosa evolui para a formação de vesículas, que em poucos dias se transformam em crostas que ao desprenderem-se deixam uma leve hipocromia residual $^{25}$.

\footnotetext{
1. Centro Municipal de Patologia Regional Argentina y Medicina Tropical, Buenos Aires, Argentina. 2. Servicio de Zoonosis (SZ). Hospital de Enfermidades Infecciosas Francisco Javier Muñiz (HIFJM). Buenos Aires. Argentina.

Endereço para Correspondência: Prof. Olindo Martino. Uspasallata 2272. Casilla Postal 1282, Buenos Aires. Argentina.

Telefax: 5411 4304-2386

E-mail: cempramt@intramed.net.ar

Recebido para publicação em 5/11/1999.
} 
Nesse trabalho se relatam quatro pacientes com rickettsioses assistidos no Hospital de Enfermidades Infecciosas Francisco Javier Muñiz, destacando-se a necessidade de incluir esta patologia dentro do diagnóstico diferencial dos exantemas febris que afetam a viajantes procedentes de áreas endêmicas.

\section{MATERIAL E MÉTODOS}

Entre março e junho de 1996 foram atendidos no Hospital de Enfermidades Infecciosas F. J. Muñiz, quatro pacientes (duas mulheres e dois homens, com um intervalo de idade entre 20 e 65 anos), os quais relataram haver estado entre uma e duas semanas anteriores ao começo da enfermidade motivo da consulta, em estreito contato com o habitat agreste de reservas naturais no sul da África. Os pacientes foram então avaliados através do método clínico e laboratorial. Nesse último foi realizada a reação de imunofluorescência indireta (RIFI) ${ }^{3}$ utilizando-se antígeno para $R$. conorii de origem comercial, e reação de aglutinação de WeilFelix, através de amostras pareadas, com intervalo de 2 a 3 semanas.

\section{RESULTADOS}

O quadro clínico se iniciou invariavelmente com a formação de uma escara escura, levemente pruriginosa. A localização da mesma foi em cada caso: a mama (Figura 1), o terço inferior da perna, no tornozelo e nas costas. Entre dois e quatro dias posteriores à aparição da lesão primária os pacientes acusaram um aumento brusco da temperatura, até $39^{\circ} \mathrm{C}$, cefaléia e astenia moderada. Em um dos casos, de uma maneira súbita

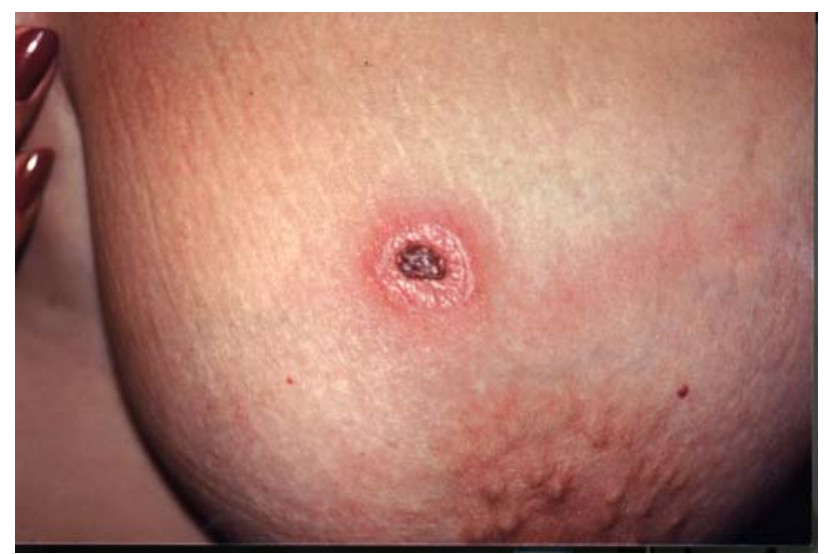

Figura 1 - Escara de inoculação na mama esquerda de uma das pacientes.

e crosta, deixando ao desprender-se uma cicatriz débil. Uma paciente apresentava uma vesícula exantemática no palato (Figura 3).

Do ponto de vista laboratorial, dois enfermos apresentaram leucocitose com neutrofilia e eritrosedimentação aumentada. Em todos os casos observou-se soroconversão à RIFI, tendo os soros analisados através da reação de Weil-Felix apresentados o resultado negativo em todos os casos.

Diante da presunção diagnóstica de rickettsiose, iniciou-se o tratamento com doxiciclina, via oral, à razão de $200 \mathrm{mg}$ por dia, durante 10 dias. A evolução foi favorável em todos os casos.

\section{DISCUSSÃO}

A presença de enfermidade febril, precedida por uma escara localizada na pele, juntamente com a ocorrência ou não de exantema, em pacientes provenientes de apareceu um exantema exclusivamente máculo-papular e de evolução fugaz, enquanto nos três casos restantes o mesmo foi pápulo-vesiculoso. As escassas lesões vesiculares se sobrepunham a uma base eritematosa e endurecida, algumas delas insinuando umbilicação central, e se distribuindo universalmente, incluindo palmas das mãos e plantas dos pés. Em dois casos as vesículas evoluíram para a etapa de pústula (Figura 2)

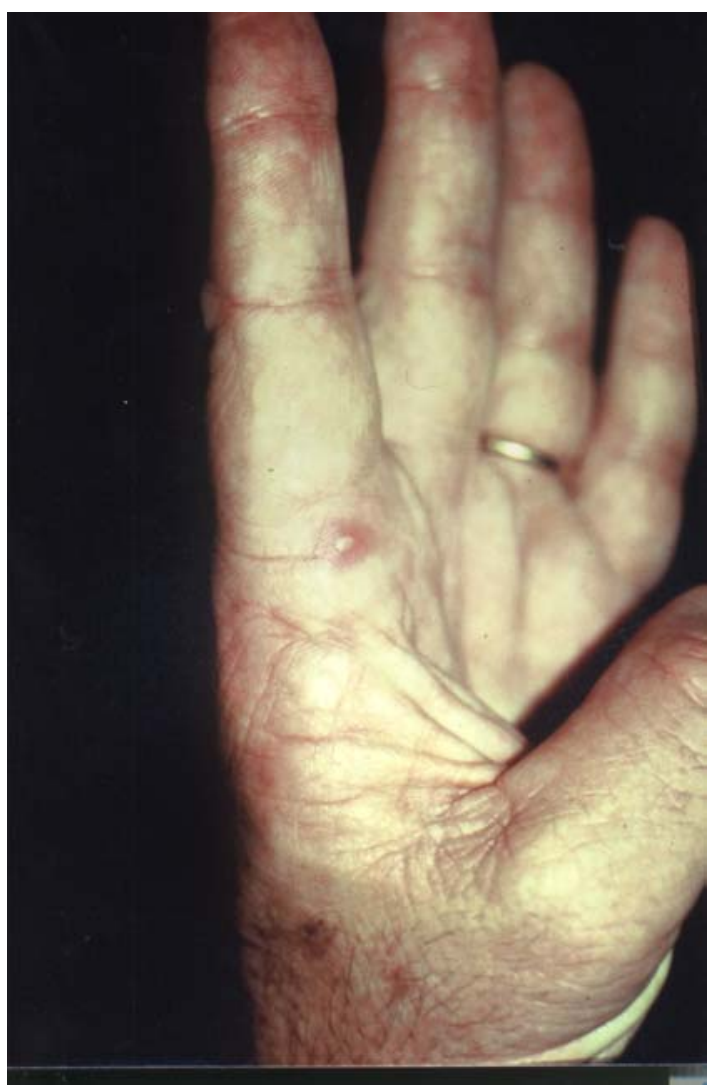

Figura 2 - Lesão pustulosa na mão esquerda de um dos pacientes.

países ou regiões tropicais ou subtropicais, obriga a incluir no diagnóstico diferencial as enfermidades por rickettsias. É importante destacar nesse ponto, que tanto 
os aspectos clínicos como epidemiológicos referidos por nossos pacientes foram compatíveis com certos modelos de enfermidades rickettsiais, particularmente as pertencentes ao grupo das febres maculosas ${ }^{214}$. Entre elas, a denominada febre africana por picada de carrapatos, cujos agentes etiológicos possíveis são $R$. conorii e $R$. africae, pode apresentar distintas epidemiologias e formas clínicas ${ }^{5}{ }^{13}$. A $R$. conorii se apresenta sob a forma de casos isolados, sendo a enfermidade adquirida com freqüência em áreas urbanas devido ao comportamento de seu vetor, Rhipicephalus sanguineus, ectoparasita do cão. No caso da $R$. africae, o vetor, Amblyomma hebraeum, é parasita do gado. Desta maneira a enfermidade se contrai em áreas rurais. Neste último caso, pelo comportamento mais agressivo do carrapato, se encontram casos clínicos simultâneos e em ocasiões múltiplas escaras de inoculação nos pacientes ${ }^{5}$.

Quanto as características clínicas, ambas as enfermidades seguem um curso similar. A presença de exantema é algo menos frequente quando o agente etiológico é $R$. africae e os sintomas podem ser mais leves ${ }^{4}$.

$O$ diagnóstico da enfermidade pode ocorrer através da sorologia. Os antígenos comerciais para imunofluorescência indireta, se obtém de $R$. conorii e mostram reação cruzada com outros agentes das febres maculosas, incluindo $R$. africae ${ }^{717}$. A diferenciação sorológica entre estes dois agentes só pode ocorrer através de adsorção cruzada ou western blotting.

Outros métodos de diagnóstico são o isolamento em cultivo de tecido e a reação de polimerase em cadeia (PCR) com primers espécie específicos. 0 melhor material para estes estudos é o tecido obtido da profundidade da escara ${ }^{5}$.

Em nossa casuística, os quatro pacientes mostraram soroconversão frente ao antígeno de $R$. conorii. Utilizando a prova de Weil-Felix, o resultado foi uniformemente negativo.

Frente às características clínicas inicialmente observadas, outros diagnósticos poderiam ser considerados: varicela, rubéola, picada de insetos, exantemas por hipersensibilidade, entre outros ${ }^{217}$. Porém as evidências clínicas e sorológicas conduzem ao

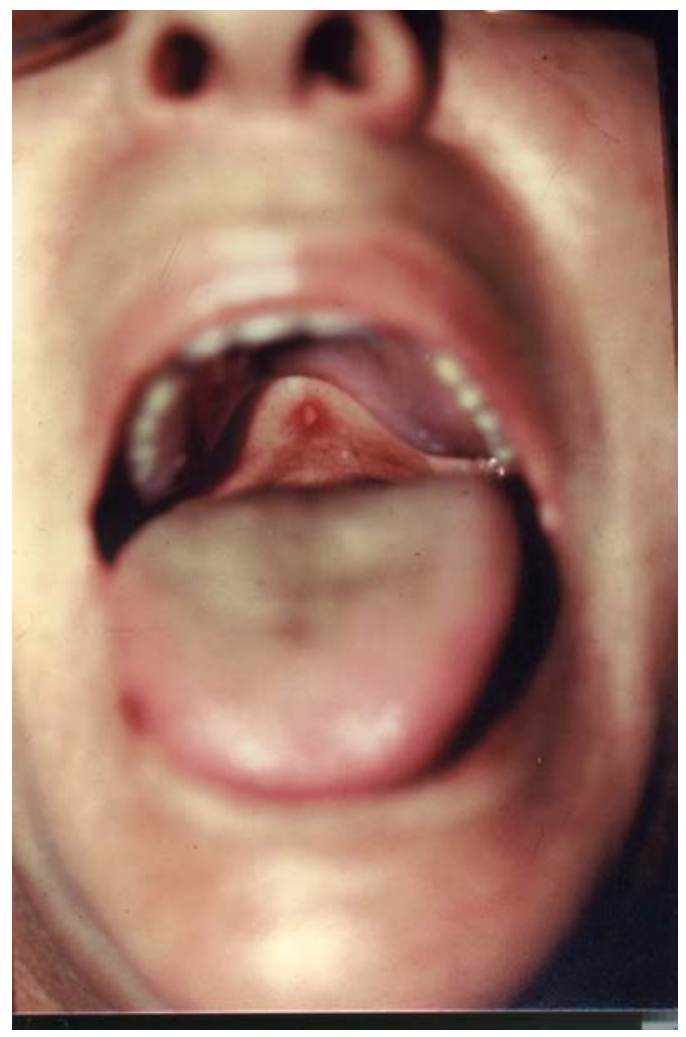

Figura 3 - Vesícula no palato mole de uma das pacientes.

diagnóstico de uma doença por rickettsia, devendo ainda no diagnóstico diferencial ser considerada a possibilidade de rickettsiose causada pela Rickettsia akari, Rickettsialpox, passível de confusão clínica e sorológica com a rickettsiose causada por $R$. conorii e $R$. africae.

Os agentes rickettsiais são sensíveis às tetraciclinas, quinolonas e macrolídeos, sendo resistentes aos agentes que atuam sobre a parede bacteriana por carecerem desta ${ }^{8} 17$.

As infecções aqui apresentadas, denominadas até pouco tempo atrás enfermidades exóticas, hoje devem ser incluídas no vasto capítulo da medicina do viajante ${ }^{18}$.

\section{REFERÊNCIAS BIBLIOGRÁFICAS}

1. Acha P, Szyfres B. Febre Botonosa. In Zoonosis y enfermidades transmisibles comunes al hombre y a los animales. $2^{\text {a }}$ ed. Publicación Científica OPS № 503 p 262-264, 1986.

2. Cowan GO. Rickettsial Infections. In Cook GC (ed) Manson's Tropical Diseases, 20a ed. Saunders, Londres. P. 797-816, 1996.

3. De Mico C, Raoult D, Toga M. Diagnosis of Mediterranean spotted fever by using na immunofluorescence technique. Journal of Infectious Diseases 153:136-138, 1986.

4. Fournier PE, Beytout J, Raoult D. Tick-transmitted infection in Transvaal: Consider Rickettsia africae. Emerging Infectious Diseases 5:178-180, 1999.
5. Fournier PE, Roux V, Caumes E, Donzel M, Raoult D. Outbreak of Rickettsia africae infections in participants of an adventure race in South Africa. Clinical Infectious Diseases 27:316-323, 1998.

6. Galvão MAM. A febre maculosa em Minas Gerais: um estudo sobre a distribuição da doença no Estado e seu comportamento em área de foco peri-urbano. Tese de Doutorado, Universidade Federal de Minas Gerais, Belo Horizonte, MG, 1996.

7. Hechemy KE. Stevens RW, Sasowskis S, Michaelson EE, Casper EA, Philip RN. Discrepances in Weil Felix and immunofluorescence test: results of Rocky Mountain spotted fever. Journal of Clinical Microbiology 9:292-293, 1979. 
8. Maurin M, Raoult D. In vitro susceptibilities of spotted fever group Rickettsiae and Coxiella burnetti to clarithromycin. Antimicrobial Agents and Chemiotherapy 37:2633-2637, 1993.

9. Mazza S, Jörg M. Estudio anatomopatológico e histopatológico de um miembro inferior amputado por gangrena, en caso de Tifus exantemático de Tinogasta. In IX Reunión de la Sociedad Argentina de Patologia Regional del Norte. Tomo III, 1935.

10. Meles HH, Colombo S, Silva M. Febre maculosa: isolamento de Rickettsia em amostra de pele. Revista do Instituto de Medicina tropical de São Paulo 34:37-41, 1992.

11. Pedreira W, Mazini A, Di Lorenzo S. Fiebre Botonosa del mediterráneo: primer foco en las Américas. In resúmenes del $1^{\circ}$ Congreso Latinoamericano de Infectologia. Córdoba, Argentina. Resumen 220/90, 1994.

12. Raoult D, La Scola B, Enea M, Fournier PE, Roux V, Fenollar F, Galvão MAM, Lamballerie X. A flea-associated rickettsia pathogenic for humans. Emerging Infectious Diseases 7:73-81, 2001.

13. Raoult D, Zuchelli P, Weiller PJ, Charrel C, San Marco JL, Gallais $\mathrm{H}$, Casanova $\mathrm{P}$. Incidence, clinical observation and risk factors in the severe from of Mediterranean spotted fever among patients admitted to the Hospital in Marseille. Journal of Infection 12:111116, 1986.

14. Saah AJ. Rickettsiosis. In: Mandell GL, Bennett JE, Dolin R (eds) Principles and Practice of Infectious Diseases $4^{\mathrm{a}}$ ed. Churchill Livingston. New York, p 1719-1720, 1995.

15. Seijo A, Cernigoi B. Relevamiento serológico en problación com riesgo de infección por Coxiella burnetti en la República Argentina. In resumenes del $1^{\circ}$ Congreso Latinoamericano de Infectologia. Córdoba, Argentina. Resumen 144/90, 1994.

16. Walker DH, Gear JM. Correlation of the distribution of Rickettsia conorii, microscopic lesions and clinical features in South African tick bite fever. American Journal of tropical Medicine and Hygiene 34:361-371, 1985.

17. Walker DH, Raoult D. Rickettsia rickettsii and other spotted fever group Rickettsiae. In Mandell GL, Bennett JE, Dolin R (eds) Principles and Practice of Infectious Diseases $4^{\circ}$ ed. Churchill Livingston. New York, p 1221-1227, 1995.

18. Wolfe MS. Travel medicine and travel clinics. Infectious Disease Clinics of North America 2:377-391, 1991. 